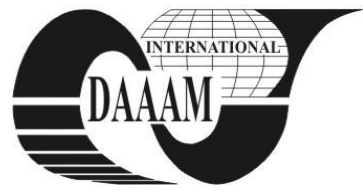

Annals of DAAAM for 2011 \& Proceedings of the 22nd International DAAAM Symposium, Volume 22, No. 1, ISSN 1726-9679 ISBN 978-3-901509-83-4, Editor B. Katalinic, Published by DAAAM International, Vienna, Austria, EU, 2011 Make Harmony between Technology and Nature, and Your Mind will Fly Free as a Bird Annals \& Proceedings of DAAAM International 2011

\title{
DESIGN FOR MANUFACTURING AND ASSEMBLY AND CAE TOOLS: THE CASE OF A RICE HUSKER
}

\author{
PINZON CHICA, R[oger] J[esus]; LASCANO, S[heila] K[atherine] \& MAURY - RAMIREZ, H[eriberto]
}

\begin{abstract}
This paper presents an advantageous and newfangled approach where the combination of Design for Manufacture and Design for Assembly with product architecture principles, complemented with CAE tools, is used to reduce the manufacturing costs, time to market and the design deliverables quality of a mechanical system are improved. The results presented were obtained from the application of this approach to the design of a rice husker. The presented case, use some novelty concepts as hot/warm/cold swapping, which were adopted from electronics field, represented and defined from design and life cycle perspective for mechanical systems

Key words: design for manufacturing and assembly (DFMA), product architecture, design for $X$ - DFX and CAE tools
\end{abstract}

\section{INTRODUCTION}

The process of rice milling involves the removal of hulls and bran from rough rice to produce polished rice. The milling equipment, often referred to as husker, hullers or shellers, removes the husk from the grain. The rubber roll paddy husker consists of two closely spaced rubber rollers rotating in opposite directions at different, the rollers contact creates a shearing action on rough rice, which removes the husk from the grain (Fig. 1).

Colombia is an emerging country, with a vast knowledge in rice production, such knowledge has been adopted for many companies to construct and to export rice production machinery. In spite of the previous knowledge, Colombian machinery manufacturers, must be ready to face the dynamic behavior of the global market, thus many of these companies are making enormous efforts that let them innovate and make appropriation of the top knowledge.

This paper presents a case study of a rubber rollers rice husker, designed and manufactured by a Colombian company leader in the provision of industrial facilities for rice processing, some relevant results, obtained by applying different DFX techniques, are discussed here.

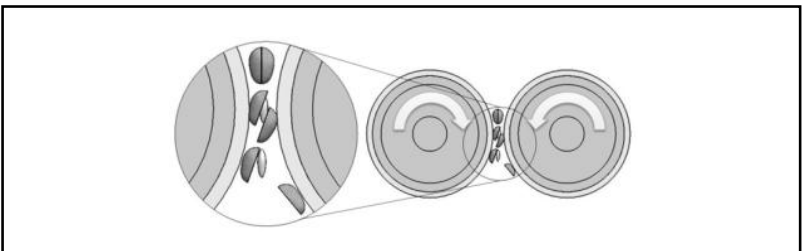

Fig. 1. Description of a rubber roller rice husker

\section{INITIAL DESIGN OF RUBBER ROLLERS RICE HUSKER}

The roller husker is less bulky than other types (Gariboldi, 1988). However this initial design was still a robust machine with many mechanical parts due the complex solutions developed to obtain an opposite roller turning and selfadjustable roller space (Fig. 4). The initial configurations of the belt transmission system and the roller space adjustment device presented clear opportunities for improvement. Additionally, there was other improvement opportunity in the initial design of support structure manufactured with welding steel plates of high thickness.

\section{METHODOLOGY}

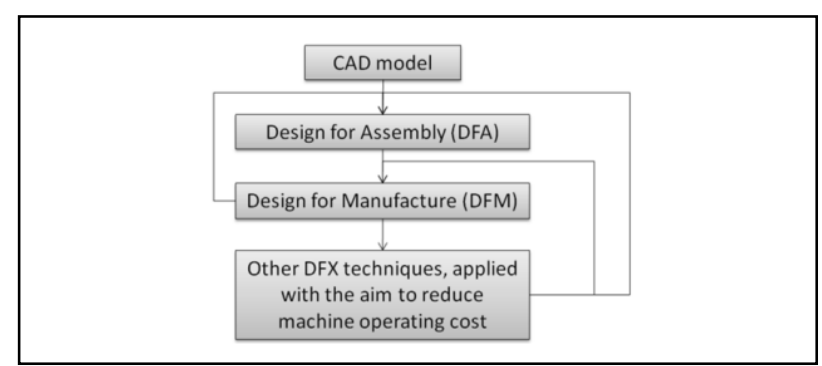

Fig. 2. Implemented methodology

The methodology applied consists of three parts (Fig. 2), it begins with a CAD model of the overall system, as the source of the information required.

The first step consists in applying DFA (Design for Assembly) guidelines, whose aim is to minimize the effort in the product assembly, it simplifies the product, facilitating to the product's manufacturing and its assembly (Boothroyd et al., 2002). DFA affects to the product, both the product structure like the part connections.

The second step is applying DFM (Design for Manufacturing) guidelines, whose purpose is to rationalize the product configuration from the manufacturing perspective. DFM focuses on two issues in design: the adequate selection of a manufacturing processes chain for a component and, the geometry part design optimization for the chosen processes chain.

Along to classic DFMA guidelines, the Cold Swapping and Hot Swapping concepts, brought from electronics and software fields, were applied to the interface design in the husker. These concepts must be defined and adapted for the mechanical systems, and therefore, the following design rule statements are defined considering two scenarios.

- Not running Scenario: Cold Swapping architecture interface must be used. The use of such interface implies that, for a safe replacement of components, the system must be turned off. A mechanical coupling of pins kind is employed to represent this interface.

- Running Scenario: Hot Swapping architecture interface must be used. In this type of architecture, the replacement of any part must be completed without interruption in production. It is necessary a mechanical clutch to connect and disconnect the operating module without stop. In addition, a turning table has to be installed, thus ensuring the operability of the system.

- An intermediate interface kind was also proposed, "Warm Swapping", The death time to overcome inertial loads 
(electrical, mechanical or thermal) and to restore the system operation are shorter than Cold Swapping's, but longer than Hot Swapping's. The Warm swapping interface can be achieved by the inclusion of a clutch function in the interface.

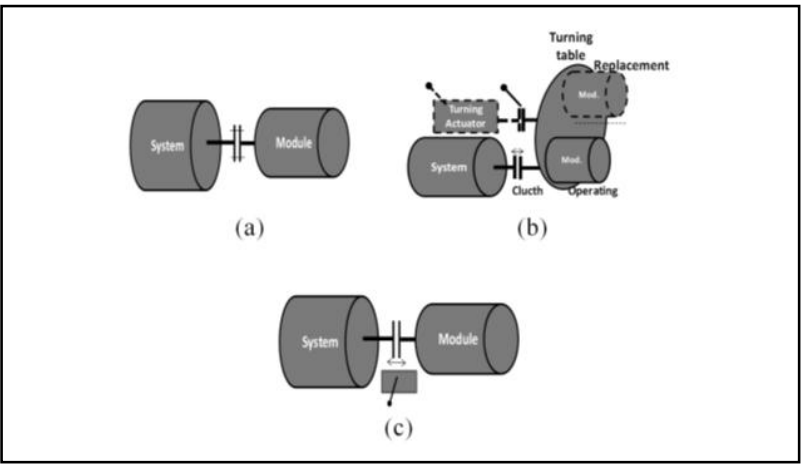

Fig. 3. Representation of (a) Cold Swapping interface type, (b) Hot Swapping interface type, (c) Warm Swapping interface architecture type

\section{RESULTS}

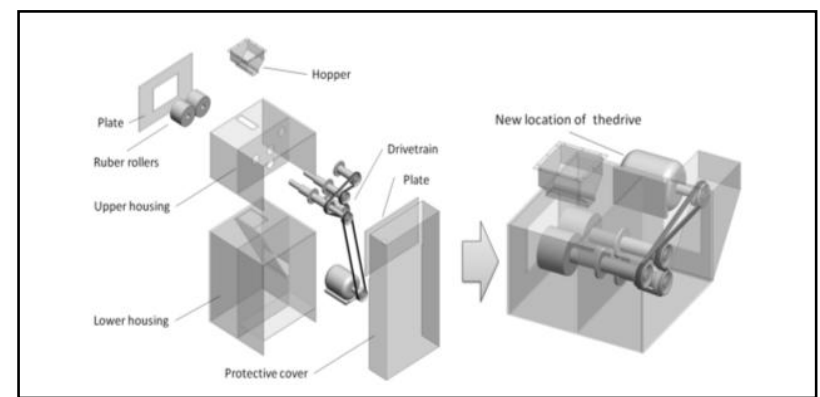

Fig. 4. Description of the previous design and the new location of the drive

One of the most significant modifications was the use of a single metal sheet in the upper housing, instead of two of them. The ideal configuration of bending for the improvement the case stiffness and reduce the stresses was determine with a FEM- CAE tools. FEM analysis were carried out at different metal sheet thicknesses for the housing, when appropriate thickness was found, the costs were compared, finding that the new design accomplished the expected performance with a considerable reduction of the overall costs. Tab. 1. summarizes the percentage of improvements achieved by the iterative use of the methodology; different metrics were used to measure the impact of the methodology.

Others of the impacts derived from the application the methodology is the relocation of the driving system. In the new design, the driving system is installed on the processing module, concentrating the processing and driving tasks in a single module.

The costs were influenced in three aspects; the first is the acquisition of raw material, in which the DFMA allowed a reduction of $7 \%$. In the fabrication of the system components the reduction was of $39 \%$ and in the assembly task the cost reduction was as much as $26 \%$. An important impact on maintainability is also expected as a result of fasteners standardization (Farias et al., 2006).

\section{CONSLUSIONS}

The methodology application reduced the number of parts of the product assembly, producing a snowball effect on cost reduction due to the drawings and specifications that are no longer needed, the reduced inventory and the no longer needed suppliers. The improvements reached in the studied case demonstrate the importance of the implementation of these methodologies in early stages of the design process, knowing that in those stages are decided most of the embodiment costs of the system.

The achieved improvements, affected the overall embodiment costs. The costs were influenced in three aspects; the first is the acquisition of raw material, in which a reduction of $7 \%$ was reached. In the fabrication of the system components the reduction was of $39 \%$ and in the assembly task the cost reduction was as much as $26 \%$.

The aid of CAD/CAE tools is essential for a successful application of the methodology. The use of software let the designer study different assembly sequences and perceives difficulties for implementation of the changes suggested by the methodology. The participation of experts (in the particular system) is necessary, to avoid misunderstand of the function carried out by some pieces.

The DFA guidelines lead to a cheaper design. However, the complexity of some pieces and the integration of functions may increase the in-service costs. Some changes may affect the structural performance or even the machine function itself, therefore special care may be taken, and some analytical tools (CAE) as FEM should be used to predict the new behavior of the system.

An important integration has been presented between Design for Manufacture, Design for Assembly and Product Architecture definition, especially in the design of the interface architectures, which have a significant impact on the assembly or disassembly times. Some novelty concepts as hot/warm/cold swapping were adopted from electronics field, represented and defined from perspective of design and life cycle of mechanical systems.

\begin{tabular}{|l|c|c|c|}
\hline \multicolumn{1}{|c|}{ Description } & $\begin{array}{c}\text { Original } \\
\text { design }\end{array}$ & Redesign & $\begin{array}{c}\text { Improvement } \\
(\%)\end{array}$ \\
\hline Assembly time (h) & 1,71 & 1,32 & $22,8 \%$ \\
\hline $\begin{array}{l}\text { Number of different } \\
\text { parts }\end{array}$ & 193 & 136 & $29,5 \%$ \\
\hline Total number of parts & 446 & 230 & $48,4 \%$ \\
\hline $\begin{array}{l}\text { Total number of } \\
\text { operations }\end{array}$ & 1845 & 951 & $48,5 \%$ \\
\hline $\begin{array}{l}\text { Metal fabrication time } \\
\text { (h) }\end{array}$ & 65,1 & 39,3 & $39,6 \%$ \\
\hline Weight (Kg) & 390,7 & 284,7 & $27,1 \%$ \\
\hline
\end{tabular}

Tab. 1. Comparison of original and new designs of the processing machine

\section{REFERENCES}

Boothroyd, G., Dewhurst, P., \& Knight, W. (2002). Product Design for manufacture and Aseembly (2nd Edition ed.). New Yory, NY: Marcel Dekker

Farias, P., Aca, J., Molina, A., Maury, H., \& Riba, C. (2006). Evolución de los modelos del proceso de diseño. In C. Riba, \& A. Molina, Ingeniería Concurrente: Una visión integradora (pp. 21-36, 107-122). Barcelona: Ediciones UPC

Gariboldi, F. (1988). Rice Milling equipment, operation and maintenance. Rome: Food and Agricultural Organitations (FAO) of the United Nations

Maury, H., Niebles, E., \& Torres, J. (2009). Diseño para la fabricación y ensamblaje de productos soldados (Design for Manufacture and Assembly of welded products). Barranquilla: Ediciones Uninorte

Otto, K., \& Wood, K. (2001). Product Design: Thechniques in reverse Engineering and new Product Development. New Jersey, NY.: Prentice Hall 